\title{
Voltaire, Pierre le Grand, la cour de Russie et la presse francophone éditée en Russie au milieu du XVIII ${ }^{\mathrm{e}}$ siècle $^{1}$
}

\author{
Vladislav Rjéoutski \\ Deutsches Historisches Institut Moskau \\ vladislav.rjeoutski@dhi-moskau.org
}

\begin{abstract}
Резюме
Публикации, посвященные Вольтеру в журнале «Caméléon littéraire» (1755), который издавал в Петербурге барон де Чуди, секретарь фаворита российской императрицы И.И. Шувалова, показывают, что до заказа Вольтеру «Истории Российской империи в царствование Петра І», Петербургский двор рассматривал великого писателя и историка как своего идейного врага. В статье доказывается, что Чуди был также автором трех текстов на французском языке о Петре, опубликованных чехословацким ученым В. Черным. Атрибуция этих текстов Чуди позволяет лучше понять не только эволюцию отношения российского двора к Вольтеру и логику пропагандисткой политики России в это время, но и архитектуру ее пропагандисткой машины и роль, которая отводилась в ней франкоязычной прессе, издававшейся в России, до официального обращения Шувалова $к$ Вольтеру с просьбой стать историографом русского императора.
\end{abstract}

\section{Mots clé}

presse francophone en Russie ; Pierre le Grand ; Voltaire ; Lomonossov ; Ivan Chouvalov ; baron de Tschudy ; propagande russe ; Caméléon littéraire

En 1755, un journaliste français écrit sur Voltaire dans un journal francophone paraissant à Saint-Pétersbourg :

Le fameux Chantre de Henri sera toujours à mes yeux un Philosophe sans principes, un Historien de mauvaise foi ; [...] lorsque l'on n'est pas sûr de ce q ue l'on avançe on doit prendre le parti du silence, singuliérement lorsqu'il est question d'un grand homme. Le nom de Pierre I. est trop réspectable et trop auguste pour oser rien hazarder, qui ne soit conforme au vrai, l'Auteur de Zaïre me saura gré, j'espere de ne pas lui citer plus précisement sa faute à cet égard. C'est un affront que je lui épargne aux yeux de tout l'Univers ${ }^{2}$.

Sept ans plus tard, en 1762, dans un autre périodique francophone publié sur les presses de l'université de Moscou, un autre journaliste français écrit à propos de l'Histoire de l'empire de Russie sous le règne de Pierre le Grand de Voltaire :

On ne risque rien en promettant qu'on reconnoitra toujours le grand homme dans ce nouvel ouvrage. On y retrouvera ces traits frappans, ce jugement sûr, cet Esprit Philosophique qui a

\footnotetext{
${ }^{1}$ Je remercie chaleureusement les collègues qui m’ont fait part de leurs conseils lors de la préparation de cet article : Wladimir Berelowitch, Sergueï Karp, Michel Mervaud, Kirill Ospovat et Vladimir Somov. Je remercie également mes collègues de la bibliothèque de l'Institut historique allemand à Moscou et, en particulier, Larissa Kondratieva, ainsi que le personnel de la Bibliothèque Voltaire (Bibliothèque nationale de Russie) et sa directrice, Natalia Speranskaïa, pour leur aide.

${ }^{2}$ Le Caméléon littéraire, $\mathrm{n}^{\circ} 7$, du 16 février 1755, p. 146-147. Toutes les citations reproduisent fidèlement l'orthographe de l'original.
} 
toujours percé dans ce qu'il a fait ${ }^{3}$.

Des avis si opposés, reflètent-ils seulement les positions de ces auteurs? Qu'est-ce qu'ils nous apprennent sur les relations entre les premiers périodiques francophones russes et les autorités de ce pays ? Peuvent-ils nous renseigner sur l'évolution de l'attitude de la cour de Russie à l'égard de Voltaire ? Voilà quelques questions auxquelles j'essaierai de répondre dans cet article.

\section{La presse francophone en Russie sous Elisabeth}

Sous le règne d'Elisabeth (1741-1761/1762), trois périodiques en langue française sont édités en Russie 4 . L'un d'entre eux est une gazette officielle consacrée à l'actualité politique, notamment aux événements de la guerre de Sept Ans (Gazette de Saint-Pétersbourg). Les deux autres sont des entreprises individuelles de deux hommes de lettres français expatriés en Russie: le baron Henri-Théodore de Tschudy (éditeur du Caméléon littéraire, SaintPétersbourg, 1755) et Philippe Hernandez (éditeur du Journal des sciences et des arts, Moscou, 1761-1762).

Ces deux derniers périodiques sont fort différents aussi bien du point de vue de leur politique éditoriale que vus sous l'angle de leurs liens avec la cour de Russie. Le Caméléon littéraire est fondé par le secrétaire du favori de l'impératrice, Ivan Chouvalov. Le journal est soutenu par l'Académie des sciences, sans doute non sans l'appui de Chouvalov et en tout cas avec celui de Kirill Razoumovski, directeur de l'Académie. Mais c'est en même temps une entreprise individuelle, Tschudy en est le rédacteur et le principal auteur ${ }^{5}$. La position du rédacteur est donc ambigüe : formellement indépendant, il est en vérité étroitement lié à quelques personnages en vue de la cour de Russie ${ }^{6}$. Ce n'est donc pas un hasard si les publications du Caméléon littéraire font constamment écho à la politique culturelle d'Ivan Chouvalov et ce, dans plusieurs domaines dans lesquels Chouvalov est alors actif : l'éducation ${ }^{7}$, le développement de la littérature nationale et l'émulation littéraire ${ }^{8}$ et, bien sûr,

\footnotetext{
${ }^{3}$ Journal des sciences et des arts, Moscou, $1762, \mathrm{n}^{\circ} 1$. Le seul exemplaire existant de ce premier numéro du deuxième volume de ce journal se trouve à la Bibliothèque de Voltaire (Bibliothèque nationale de Russie), ex libris : $\operatorname{arm} 8, \mathrm{n}^{\circ} 292$. Je remercie Vladimir Somov de m’avoir communiqué cette information.

${ }^{4}$ Sur la presse francophone en Russie, voir Vladislav Rjéoutski et Natalia Speranskaïa, « The Francophone Press in Russia: A Cultural Bridge and an Instrument of Propaganda ", Derek Offord, Lara Ryazanova-Clarke, Vladislav Rjéoutski, Gesine Argent (éd.), French and Russian in Imperial Russia, vol. 1, Language Use among the Russian Elite, Edimbourg : Edinburgh University Press, 2015, p. 84-102.

${ }^{5}$ Tous les textes publiés dans ce journal peuvent lui être attribués et portent la marque de son style, à l'exception de quelques publications dues à des auteurs russes (Grigori Teplov) et occidentaux (Mme Leprince de Beaumont, Mme du Bocage, etc.).

${ }^{6}$ Sur cette revue et son rédacteur, voir A.Н. Попова, «Теодор-Генрих Чуди и основанный им в 1755 г. журнал "Le Caméléon littéraire"», Известия АН СССР. Отдел гуманитарных наук [A.N. Popova, "Théodore-Henri de Tschudy et le journal Caméléon littéraire fondé par lui en 1755 », Le Bulletin de l'Académie des sciences de l'URSS. Section des humanités], $\mathrm{n}^{\circ}$ 1, Moscou, 1929, p. 17-48; Antoine Nivière, "L'affaire Tschudi », Slovo, 20oo, vol. 24-25, p. 297-396 ; Michel Mervaud, «Des matériaux pour Voltaire : une lettre du baron Théodore Henri de Tschoudy à Gerhard Friedrich Müller (septembre 1759) », Les Archives de l'Est et la France des Lumières, sous la dir. de Georges Dulac et de Sergueï Karp, Ferney-Voltaire : CIEDS, 2007, vol. 2, p. 422-432 ; В. Ржеуцкий, «В тени Шувалова: Французский культурный посредник в России барон де Чуди», Новое Литературное Обозрение [Vladislav Rjéoutski, «A l'ombre de Chouvalov: Un intermédiaire culturel français en Russie, le baron de Tschudy », Novoé litératournoé obozrénié], n ${ }^{\circ}$ 105, 2010, p. 91-124.

${ }^{7}$ Voir par exemple, Vladislav Rjéoutski, «Un journaliste français héraut de l'éducation publique en Russie », Quand le français gouvernait la Russie, textes et études réunis et présentés par Vladislav Rjéoutski, Paris, L'Harmattan, 2016, p. 233-243.

${ }^{8}$ Voir К. Осповат, «Государственная словесность: Ломоносов, Сумароков и литературная политика И.И.
} 
la glorification de la Russie et sa souveraine.

Le Journal des sciences et des arts semble être plus indépendant. Philippe Hernandez, journaliste ayant contribué au Journal Etranger, se trouve à Moscou où il est amené à exercer le métier de précepteur. Il décide en 1761 de faire valoir ses compétences de journaliste et de faire paraître un journal de recensions de travaux publiés en Europe occidentale et, plus rarement, en Russie. Ce journal l'aide à faire écouler les livres qu'il reçoit principalement de Marc-Michel Rey, célèbre éditeur hollandais ${ }^{9}$. Le journal d'Hernandez est tiré sur les presses de l'université de Moscou. Chouvalov, le grand patron de l'université, n'a-t-il pas soutenu aussi cette publication?

\section{Voltaire et la société russe au milieu du XVIII siècle}

Certainement le premier écrivain russe à avoir subi l'influence de Voltaire a été le prince Antioche Kantemir, très intéressé par la littérature française. Ses contacts avec plusieurs écrivains occidentaux ont été facilités grâce au fait qu'il s'est trouvé successivement à Londres et à Paris comme représentant diplomatique de la Russie ${ }^{10}$. Kantemir est l'un des premiers Russes à s'être essayé à traduire des œuvres de Voltaire. Quelques traductions du grand écrivain sont également sorties dans le journal russe Euvres mensuelles pour lier l'utile et l'agréable, publié par l'Académie des sciences pétersbourgeoise, premier périodique en langue russe à tendance littéraire. Les Euvres mensuelles ont publié (1756) la traduction de Micromégas" ${ }^{11}$ faite par le jeune Alexandre Vorontsov, neveu du vice-chancelier de l'Empire de Russie, (1756) celle de Memnon ou la Sagesse humaine ${ }^{12}$, par le même Vorontsov, et, enfin (1759) celle de Zadig, anonyme cette fois ${ }^{13}$. Comme l'a montré Piotr Zaborov, le jeune traducteur a dû faire face à nombre de difficultés, certaines ont été insurmontables pour lui, surtout dans la traduction du lexique, le traducteur ne connaissant souvent pas les mots correspondants en russe. Il est aussi intéressant que, dès cette époque, Voltaire fait l'objet d'une certaine censure, assez modérée, il est vrai, qui porte sur des passages équivoques, particulièrement concernant les femmes ${ }^{14}$.

Шувалова в конце 1750-х гг.», Европа в России: сборник статей [Kirill Ospovat, « Les belles-lettres d'Etat : Lomonossov, Soumarokov et la politique littéraire d'Ivan Chouvalov à la fin des années 1750 », L'Europe en Russie : recueil d'articles], Moscou : Novoïé litératournoïé obozrénié, 2010, p. 6-65, ici p. 19-23, 26, etc.

${ }^{9}$ Sur Hernandez, je me permets de renvoyer le lecteur à mon étude : Vladislav Rjéoutski, "Aux sources de l'histoire russe dans la France des Lumières: Philippe Hernandez et sa bibliothèque », Slavica Occitania 28, 2009, numéro spécial Naissance de l'historiographie russe, sous la dir. de Michel Mervaud et de Stéphane Viellard, Slavica Occitania 28 (2009), p. 261-294; sur ce journal, voir Vladislav Rjéoutski, «Cas de transfert culturel triangulaire : Grande Bretagne-France-Russie. Le Journal des sciences et des arts de Philippe Hernandez, Moscou, 1761 », Lise Andries, Frédéric Ogée, John Dunkley, Darach Sanfey (éd.), France, Great Britain and Ireland: Cultural Transfers and the Circulation of Knowledge in the Age of Enlightenment, Oxford: Voltaire Foundation, 2013, p. 309-322.

${ }^{10}$ Sur les échos à l'œuvre de Voltaire dans la société russe de cette période, l'étude classique reste celle de Piotr Zaborov, publiée d’abord en russe : П.Р. Заборов, Русская литература и Вольтер [P.R. Zaborov, La littérature russe et Voltaire], Leningrad, 1978 ; puis, dans une édition retravaillée, en français : Piotr Zaborov, Voltaire dans la culture russe, Ferney-Voltaire : CIEDS, 2011. Nous ne faisons que résumer ici les événements qui sont exposés avec plus de détails dans ce livre auquel nous renvoyons le lecteur.

${ }^{11}$ Ежемесячные сочинения, к пользе и увеселению служащие [Euvres mensuelles pour lier l'utile et l'agréable], janvier 1756, p. 31-61.

${ }^{12}$ Ibid., avril 1756, p. 330-338.

${ }^{13}$ Переводы и сочинения, $к$ пользе и увеселению служащие [Traductions et œuvres pour lier l'utile et l'agréable], janvier 1759, p. 58-71 ; février, p. 152-167 ; mars, p. 226-242 ; avril, p. 337-354 ; mai, p. 446-469 ; juin, p. 503-252.

${ }^{14}$ Piotr Zaborov, Voltaire dans la culture russe, op.cit., p. 18-19. 
Ayant publié deux traductions des œuvres de Voltaire en 1756, la revue a fait une pause de trois ans avant d'enchaîner, en 1759, avec Zadig. En 1759, Voltaire travaillait sur son Histoire de la Russie sous le règne de Pierre le Grand, écrite à la demande de la cour de Russie, dont il allait sortir le premier volume la même année. L'histoire de cette commande et des relations de Voltaire avec Ivan Chouvalov et, à travers lui, avec d'autres personnes ayant préparé des matériaux historiques pour l'écrivain, notamment avec Mikhaill Lomonossov, a été bien étudiée ${ }^{15}$. On sait quel rôle a joué dans cette commande Ivan Chouvalov, le favori d'Elisabeth : il en a été très probablement l'initiateur, il a collecté, fait traduire et fourni à Voltaire de nombreux documents historiques, il a transmis au philosophe de nombreuses remarques des historiens russes, y compris de Lomonossov, sur le manuscrit de son histoire, remarques qui ont été partiellement ignorées par Voltaire qui a considéré, non sans raison, qu'on faisait pression sur lui pour diriger sa plume. Or, en 1755-1756, Voltaire n'était pas encore une persona grata à la cour de Russie. Faut-il voir des raisons politiques dans cet arrêt provisoire des publications des œuvres de Voltaire par la principale revue culturelle russe ? Ce n'est pas impossible même si les preuves nous manquent pour avancer dans cette direction.

Le seul article portant sur Voltaire dans le Journal des sciences et des arts a été découvert par Vladimir Somov dans la bibliothèque de l'écrivain ${ }^{16}$. Celle-ci, on le sait, a été achetée par Catherine II après la mort du patriarche et se trouve actuellement à la Bibliothèque nationale de Russie, à Saint-Pétersbourg. Il s'agit d'une recension du premier volume de l'Histoire de l'empire de Russie sous le règne de Pierre le Grand, écrite sans doute par l'éditeur du journal. Cette publication est parue dans le premier numéro du deuxième volume de ce journal, au début de 1762. Est-ce que cette livraison a été envoyée à Ferney par Hernandez ? On ne peut évidemment pas exclure cette possibilité, mais on ne sait rien des relations de Hernandez avec l'écrivain ; on peut plutôt supposer que cela a été fait par Ivan Chouvalov pour qui la parution d'un journal francophone à Moscou, sur les presses de l'université qu'il a fondée, revêtait évidemment une importance de prestige qu'on peut parfaitement comprendre. Il est difficile d'imaginer que le favori ait manqué de communiquer à l'écrivain cette recension de l'ouvrage de Voltaire. Il semble que ce soit la seule recension de ce livre publiée en français en Russie à cette époque.

Hernandez salue l'auteur qui « refuse de sacrifier la vérité à l'esprit de parti » et cite

\footnotetext{
${ }^{15}$ Nous indiquons dans l'ordre chronologique les principaux travaux qui ont exploré cette question : Е.Ф. Шмурло, «Петр Великий в оценке современников и потомства», Журнал Министерства народного просвещения [E.F. Chmourlo, «Pierre le Grand vu par ses contemporains et les générations postérieures», Revue du ministère de l'Education nationale], 1911, $\mathrm{n}^{\circ}$ 10, 11,$12 ; 1912, \mathrm{n}^{\circ}{ }_{5}, 6$; Idem, Вольтер и его книга о Петре Великом [idem, Voltaire et son livre sur Pierre le Grand], Prague, 1929; Вольтер: Статьи и материалы [Voltaire: articles et documents], Leningrad, 1948; Dmitri Mohrenshildt, Russia in the intellectual life of eighteenth century France, New York, 1936 ; Albert Lortholary, Les "Philosophes" du XVIII siècle et la Russie. Le mirage Russe en France au XVIII siècle, Paris, 1951 ; Ф.Я. Прийма, Русская литература на Западе. Статьи и разыскания [F.Ya. Priima, La Littérature russe en Occident. Articles et recherches], Leningrad, Naouka, 1970 (chapitre «Ломоносов и «История Российской империи при Петре Великом» Вольтера», p. 58-76) ; С.Н. Wilberger, Voltaire's Russia: window on the East, SVEC, 1976, vol. CLXIV ; П.Р. Заборов, Русская литература u Вольтер [P.R. Zaborov, La littérature russe et Voltaire], Leningrad, 1978 (éd. en français : Piotr Zaborov, Voltaire dans la culture russe, Ferney-Voltaire, CIEDS, 2011) ; Д.Н. Костышин, «Из истории издания книги Вольтера о Петре Великом. Письма графа А.Г. Головкина И.И. Шувалову и Вольтеру», Исторический архив [D.N. Kostychyne, « De l'histoire de l'édition du livre de Voltaire sur Pierre le Grand : lettres du comte A.G. Golovkine à I.I. Chouvalov et à Voltaire», Istoritcheskii Arkhiv], $\mathrm{n}^{\circ} 4,1993$ (édition électronique : http://www.vostlit.info/Texts/Dokumenty/Russ/XVIII/1760-1780/Golovkin_A_G/briefe_volter_shuvalov.htm ); Voltaire, Histoire de l'empire de Russie sous Pierre le Grand, éd. critique par Michel Mervaud avec la collaboration de Ulla Kölving, Christiane Mervaud et Andrew Brown, Euvres complètes de Voltaire, Oxford : Voltaire Foundation, 1999, t. 46-47 ; С.А. Мезин, Взгляд из Европы: французские авторы XVIII века о Петре I [S.A. Mézine, Regard de l'Europe : les auteurs français sur Pierre I ${ }^{e r}$ ], Saratov, 2003.

${ }^{16}$ Bibliothèque nationale de Russie, Bibliothèque de Voltaire, Journal des sciences et des arts, vol. $2,1762, \mathrm{n}^{\circ} 1$.
} 
quelques livres partisans et parmi eux l'ouvrage sur Pierre le Grand par Nestesuranoi, c'est-àdire par le journaliste Rousset de Missy, qui, comme on sait, entretenait des relations très étroites avec la cour de Russie ${ }^{17}$. Le compte rendu de Hernandez est une suite de citations tirées de l'ouvrage de Voltaire. Hernandez cite par exemple quelques passages se rapportant à Le Fort, célèbre compagnon suisse de Pierre le Grand. Il reproduit l'extrait qui compare Charles XII, qui n'a laissé après lui que des ruines, et Pierre, qui est un " fondateur en tout genre ». Il y a aussi des citations qui glorifient l'impératrice régnante, fille du grand souverain, notamment à cause de son humanité car elle a interdit l'application de la peine de mort. L'article réussit donc, sans écrire grand chose sur le livre, à louer son auteur et son objet ${ }^{18}$.

\section{Voltaire vu par le baron de Tschudy, éditeur du Caméléon littéraire}

Bien plus intéressante et riche à cet égard est l'œuvre journalistique du baron de Tschudy ${ }^{19}$. Sans décrire la biographie de Tschudy à laquelle j'ai consacré un article à part ${ }^{20}$, je m'arrêterai sur les faits importants pour la compréhension de la position de l'éditeur. Tschudy arrive en Russie en 1752. Il est d'abord comédien dans la troupe française de la cour de Russie; il travaille, sans doute comme secrétaire, pour le baron Sergueï Grigorievitch Stroganov, richissime propriétaire d'usines métallurgiques et grand chambellan à la cour de Russie ; enfin, il devient secrétaire d'Ivan Chouvalov, nouveau favori de l'impératrice. C'est sans doute grâce à Chouvalov qu'il obtient la permission de publier un journal littéraire qui, on l'a dit, est tiré sur les presses de l'Académie des sciences pétersbourgeoise et partiellement subventionné par l'Académie.

Le nombre d'articles consacrés à Voltaire ou dans lesquels Voltaire est mentionné est relativement important dans ce journal ${ }^{21}$. Cela s'explique sans doute en partie par le caractère de ce périodique, un hebdomadaire littéraire, peut-être par l'engouement du public pour le grand auteur français et certainement par celui de l'éditeur.

Un des premiers articles du Caméléon littéraire est consacré à la dispute de Laurent Angliviel de La Beaumelle avec Voltaire à propos du Siècle de Louis XIV. Tschudy y prend fait et cause pour le philosophe en s'adressant ainsi à La Beaumelle :

[...] que le chantre de Henri, seroit un jour vilipendé par l'auteur du qu'en dira t'on ? je laisse volontiers guéroïer nos Champions, ou plutôt Mr. de la Beaumelle tout seul, puisque son adversaire ne daigne pas seulement lui rendre injure pour injure ; mais au moins qu'il ait la bonté de ne pas faire passer pour disputes littéraire [sic! - V.R.], une mauvaise chicanne qui n'intérèsse nullement les savants, et qui n'est autre chose qu'une maussade joutte de personalités et d'invectives, soutenue d'un stile vif et petillant fort de mots mais vuide de chose, Mr. de la Beaumelle écrit avec un feu que je voudrois avoir, c'est une tournure un

\footnotetext{
${ }^{17}$ Sur Rousset de Missy et ses relations avec la Russie, voir Г.А. Шатохина, « Голландский публицист Жан Руссе де Мисси и его связи с Россией » [G.A. Chatokhina, «Le journaliste hollandais Jean Rousset de Missy et ses relations avec la Russie »], Russia and the Low Coutries in the Eighteenth Century / Россия и Нидерланды в XVIII веке, ed. Emmanuel Waegemans, Groningen, 1998, p. 111-123 ; С.А. Мезин, « Голландский публицист Жан Руссе де Мисси как биограф Петра I », Россия - Нидерланды. Диалог культур в европейском пространстве. Материалы V Международного петровского конгресса [« Le journaliste hollandais Jean Rousset de Missy comme biographe de Pierre $\mathrm{I}^{\mathrm{er}}$ ", Russie - Pays Bas. Dialogue des cultures dans l'espace européen. Actes du $V^{e}$ Congrès international Pierre le Grand], Saint-Pétersbourg, 2014, p. 442-457.

${ }^{18}$ Voir le texte de cette recension en annexe.

${ }^{19}$ Les articles consacrés à Voltaire ont été analysés par Piotr Zaborov, op.cit., p. 14-17. Cependant, on s'arrêtera plus en détail sur ces articles car nos conclusions ne coïncident pas en tout point.

${ }^{20}$ В. Ржеуцкий, «В тени Шувалова», art. cit.

${ }^{21}$ Voir, en annexe, tous les articles du Caméléon littéraire qui traitent de Voltaire.
} 
Phrasisme séduisant, mais est on auteur à ce prix $?^{22}$

\section{Il continue :}

Ne vaudroit il pas mieux cesser de vivre que d'exciter en vous ce sentiment dont votre orguëil se pare : il vous sied mal sur le ton de censeur de passer en revüe les ouvrages d'Aroüet; je le disois avant hier vous êtes à $M r$. de Voltaire ce qu'est un point géometrique au nombre 100o, car enfin, un petit retour sur vous même ${ }^{23}$.

\section{Et il conclue :}

Quant à l'esprit, au savoir, au mérite, au talent, pavillon bas : ou si vous étés assés vain pour vous croire au pair d'un grand homme, et en même tems assés teméraire pour le mépriser, faites usage du conseil que vous lui donés vous-même «le mépris est froid, et vous l'étes si peu : soïés le donc ${ }^{24}$.

On voit donc que l'attaque de Tschudy sur La Beaumelle est virulente et que le journaliste est entièrement du côté de Voltaire, qu'il vénère ${ }^{25}$.

Dans la livraison suivante, du 12 janvier, le journaliste parle des pièces attendues de Voltaire et de Crébillon, «frapés tous deux de main de maître ils peuvent être également beaux chacun dans leur espèce ${ }^{26}$. Il mentionne à nouveau Voltaire dans ses « Nouvelles de Paris », à propos d'une représentation de Nanine, qui a eu cette fois-ci, dit Tschudy, un « succès prodigieux $»^{27}$.

Dans la livraison du 16 février 1755, le journaliste publie un article intitulé « Réflexions d'une femme d'esprit ». Celui-ci n'annonçait rien de particulier, mais il se termine par des commentaires de l'éditeur dans lesquelles on trouve, d'une façon inattendue, cette admonestation que j'ai citée au début de l'article : Voltaire y est accusé d'être un "Philosophe sans principes » et un « Historien de mauvaise foi ». Tschudy va même plus loin, en affirmant que « ce terme n'est pas trop fort » car « il est absurde à un quelqu'un qui detaille des faits historiques de s'excuser, en disant qu'il a peutetre été mal informé ${ }^{28}$.

Une semaine plus tard, dans la livraison du 23 février, l'éditeur écrit de nouveau sur Voltaire. On pouvait s'attendre à la continuation des critiques commencées dans la livraison précédente, cependant, l'éditeur reprend le ton admiratif de ses premières publications sur Voltaire. Cette fois-ci, Tschudy prend fait et cause pour la position de l'écrivain au sujet des changements de l'orthographe. En souscrivant entièrement au «système » de Voltaire, Tschudy écrit :

Monsieur de V..... est d'un mérite distingué et reconu : l'admiration que j'ai pour ce grand homme n'est pas cependant le motif qui me décide en faveur de son Ortografe. On peut être excellent Poète, bon Historien, Philosophe habile, sans conaître à fond les règles de l'Ecriture,

\footnotetext{
${ }^{22}$ Le Caméléon littéraire, $\mathrm{n}^{\circ}$, du 5 janvier, p. 3-4.

${ }^{23}$ Ibid., p. 4.

${ }^{24}$ Ibid., p. 4.

${ }^{25}$ Il est donc difficile d'être d'accord avec l'avis de Piotr Zaborov qui écrit que « la revue tenta, dans la mesure du possible, de rester impartiale et de ne manifester sa sympathie à aucune des parties en lice ». Piotr Zaborov, Voltaire dans la culture russe, op.cit., p. 14-15. Ici et infra je ne résume pas tout le contenu de ces articles que le lecteur retrouvera en annexe, mais me borne à en noter le ton général à l'égard de Voltaire, qui nous permettra de comprendre l'évolution de l'attitude de ce journal envers l'écrivain.

${ }^{26}$ Le Caméléon littéraire, $\mathrm{n}^{\circ}$ 2, du 12 janvier 1755, p. 38-44.

${ }^{27}$ Le Caméléon littéraire, ${ }^{\circ}$ 6, 9 février 1755, p. 128-131.

${ }^{28}$ Le Caméléon littéraire, $\mathrm{n}^{\circ}$ 7, du 16 février 1755, p. 146-147.
} 
cet article est du ressort du Grammairien, Monsieur de V... ne serait pas moins un grandhomme quand il l'ignorerait. Ce n'est donc pas l'esprit de parti n'y la prévention qui me guide ; l'Evidence seule a droit de me convaincre ${ }^{29}$.

Il est d'autant plus étonnant de lire ces lignes que Tschudy y mentionne l'œuvre historique de Voltaire : une semaine avant, celui-ci était un historien "de mauvaise foi », maintenant il redevient «bon historien ». On voit donc que Tschudy agit comme une girouette (ou, si l'on veut, comme un « caméléon littéraire ») changeant d'attitude à l'égard de l'écrivain en l'espace de quelques jours.

Le journaliste continue de publier sur Voltaire dans les livraisons suivantes de son journal. Ainsi, le 9 mars, il résume la dissertation sur le théâtre ancien et moderne placée à la tête de Sémiramis de Voltaire, contribuant ainsi à faire mieux connaître l'œuvre de l'écrivain en Russie $^{30}$. Voltaire continue d'être mentionné, parfois au passage, mais toujours avec cet air d'admiration qu'on a vu chez Tschudy. Ainsi, dans la livraison du 23 mars, le journaliste fait cette remarque : «Monsieur de VOLTAIRE a donné un discours assés fort dans ses pièces de litteratures sur ce que l'on ne fait pas, \& sur ce qu'on devrait faire $»^{31}$.

L'article du 6 avril 1755, intitulé «Lettre de l'auteur à son ami », est particulièrement intéressant. Tschudy y expose, avec une franchise digne d'être remarquée, les griefs qu'on lui a faits au sujet de ses publications - il est accusé de légèreté - et, notamment, au sujet de sa «voltairomanie » : «Bon Dieu! que ne gardiés-vous cette mort de CICÉRON ${ }^{32}$, dont pour mon malheur j'ai pensé trop haut, on m'acuse de VOLTAIROMANIE ${ }^{33}$. Tschudy se permet de riposter par une sortie un peu insolente : « Eh bien ! dorenavant je dirai que Catilina ${ }^{34}$ vaut mieux que Rome sauvée $e^{35}$, que Rhadamiste $e^{36}$ est au dessus de Zaïre $e^{37}$ : mais on ne me croira pas, que faire ? je ne dirai rien : il est trop dangereux de parler $»^{38}$. Et d'une façon plus claire encore : «Voilà, mon cher Ami, les griefs que l'on a contre moi, je ne puis y répondre c'est ce qui me désole. Et par quelle raison dirés-vous ; parcequ'il me sied mal de luter contre des persones que je respecte \& de l'avis desquelles je voudrais toujours être. Tenés, par exemple, votre fatal Triumvirat me met dans le cas de contredire un des Esprits les plus respectables, les plus polis \& les plus cultivés ${ }^{39}$. Il parle de toute évidence de sa discussion de deux pièces : le Triumvirat de Crébillon et La Mort de Cicéron de Voltaire, dont il est question dans la livraison du 12 janvier 1755 ; puis, le 9 février, il signale l'échec du Triumvirat sur scène : « la montagne a encore accouché d'une souris $»^{40}$, écrit-il. Ayant ainsi clairement fait comprendre que sa prose faisait l'objet de censure, Tschudy se rattrape tout de suite, à propos d'une phrase qui n’a apparemment pas été du goût de tous ses lecteurs, en caressant, d'une manière

\footnotetext{
${ }^{29}$ Le Caméléon littéraire, ${ }^{\circ}$ 8, du 23 février, p. 167-176, « Apologie de l'orthografe de M. de V.... », ici p. 169-170.

${ }^{30}$ Le Caméléon littéraire, $\mathrm{n}^{\circ}$ 10, du 9 mars 1755, p. 222-229.

${ }^{31}$ Le Caméléon littéraire, $\mathrm{n}^{\circ} 12$, du 23 mars 1755, p. 270.

${ }^{32}$ Tschudy a parlé de la Mort de Cicéron, de Voltaire, dans ses articles du 12 janvier et du 9 février 1755 , en comparant cette pièce au Triumvirat de Crébillon.

${ }^{33}$ Le Caméléon littéraire, $\mathrm{n}^{\circ}$ 14, du 6 avril 1755, p. 305-306.

34 Tragédie de Crébillon-fils.

${ }^{35}$ Rome sauvée, ou Catilina, par Voltaire.

${ }^{36}$ Rhadamiste ou Zénobie, de Crébillon-père.

37 Tragédie de Voltaire.

${ }^{38}$ Le Caméléon littéraire, $\mathrm{n}^{\circ}$ 14, du 6 avril 1755, p. 306.

${ }^{39}$ Ibid., p. 309.

${ }^{40}$ Ibid., n6, du 9 février 1755, p. 129.
} 
exagérée et ostentatoire, l’orgueil national de ses lecteurs russes :

[...] je disais que c'est trop borner le goût, le talent \& le mérite d'un pays de le réduire simplement à la Poësie, surtout quand l'expérience journelle démontre que les autres sciences, les arts y fleurissent avec un égal succès, je prétendais (car dans ce Siècle il faut développer toutes ses pensées) je prétendais que ce serait doner une trop legère Idée de la Russie, par Exemple, ne la louer qu'en partie, de publier les noms des Racines qu'elle produit, de ceux qui cherchent à s'y égaler. J'ajoutois, que, faire des vers, c'est peu de chose pour un Empire qui en fourni d'aussi grandes en tout genre ; en faire de bons, continuais-je, c'est déjà quelque chose, mais ne faire uniquement que cela, ce n'est rien. Non, rien en comparaison d'une infinité de productions utiles \& savantes qui rendent cette nation rivale du surplus de l'Europe, sans parler d'une florissante Académie formée sous les auspices du plus grand des Monarques (a) sans dire mot d'une Université naissante, \& qui s'élève sous le règne glorieux de l'auguste \& digne Fille d'un Héros (b). Les Russes n'ont-ils donc pas d'ailleurs cent endroits recomandables \& faits pour être admirés. Loix sages, gouvernement habile \& prudent, oeconomie judicieuse, armées triomphantes \& formidables, discipline militaire, police exacte, magistrature éclairée, Sénat auguste, Sénateurs dignes de l'ancienne Rome, un d'entre eux surtout plus utile à la patrie que dans le Cabinet, que les Scipions à la tête des légions, également propre néanmoins à les comander. [...]

(a) PIERRE Premier

(b) ELISABETH PETROWNA ${ }^{41}$

Il revient encore à cette polémique au sujet de Voltaire dans la livraison du 4 mai. Dans une note sur un poème intitulé "Lettre en vers au marquis de Pesée par sa maitresse ", probablement de sa plume, il écrit: "C'est être assurement bien hardi de comparer des ouvrages de Monsieur de Voltaire, sa supériorité est si bien établie, que c'est risquer beaucoup de vouloir lui trouver des défauts. Aussi n'est ce point par un de ses vers, mais seulement pour détromper ceux qui m’acusent d'une prévention assés forte pour encenser jusques aux torts de ce grand-homme, suposé qu'il en eût dans quelques uns de ses ouvrages [...] ${ }^{42}$ Suivent quelques critiques du style de Voltaire, somme toute assez limitées.

On voit donc que le journaliste est de temps en temps rappelé à l'ordre, mais que c'est essentiellement ses publications sur Voltaire qui provoquent le mécontentement des personnes que Tschudy dit « respecter » et « de l'avis desquelles » il voudrait toujours être. Mais on a aussi l'impression que ce contrôle n'est pas si sévère ou que le journaliste peut se permettre d'« oublier » ces rappels pour s'adonner de nouveau à son admiration pour le grand écrivain.

\section{Voltaire et la cour de Russie au milieu du XVIII ${ }^{e}$ siècle}

Pourquoi en 1755 Voltaire excite-t-il le mécontentement de la cour de Saint-Pétersbourg ? Rappelons brièvement le contexte historique.

En 1731, Voltaire publie son Charles XII dans lequel la figure de Pierre $\mathrm{I}^{\mathrm{er}}$ occupe déjà une place importante. Quand, en 1737, l'écrivain s'apprête à rééditer ses œuvres, il complète son livre sur le roi de Suède en voulant « entrer plus profondément dans le détail de ce qu'a fait le czar pour le bien de l'humanité ${ }^{43}$. Les accents sont déjà posés : Voltaire met plus haut Pierre,

\footnotetext{
${ }^{41}$ Ibid., n ${ }^{\circ}$ 14, du 6 avril 1755, p. 307-308.

${ }^{42}$ Ibid., n 17 , du 4 mai 1755, p. 388-391, ici p. 389.

${ }^{43}$ Voltaire à Frédéric II, mai 1737, CEuvres complettes de Voltaire, t. 44, Correspondance de Voltaire avec le roi de Prusse, Paris, chez Jean François Bastien libraire, 4 année, p. 62.
} 
qui est un créateur, que Charles, responsable de "tant de maux faits aux hommes ${ }^{44}$. En même temps, son Pierre est loin d'être idéalisé et son portrait de l'empereur suscite sans doute une certaine irritation à Saint-Pétersbourg comme on peut conclure d'après cette Réfutation écrite plus tard dans laquelle cette œuvre de Voltaire est l'objet principal de critique (voir plus loin).

Voltaire commence à réunir des matériaux sur Pierre le Grand. Le prince Frédéric, futur Frédéric II, l'aide en servant d'intermédiaire entre l'écrivain et le diplomate prussien Vockerodt qui a passé beaucoup d'années en Russie sous Pierre $\mathrm{I}^{\mathrm{er}}$ et peut renseigner l'écrivain sur ce pays. Comme l'avait déjà montré Evgueni Chmourlo, Frédéric avait une idée tout à fait positive de Pierre avant d'avoir lu les réponses de Vockerodt aux questions formulées par Voltaire. Il change maintenant son regard sur l'empereur russe et s'efforce d'influencer l'historien français, y compris en modifiant parfois le sens des réponses de Vockerodt, qui parviennent à Voltaire en traduction ${ }^{45}$. Celui-ci n'est cependant pas prêt à céder et continue de voir le tsar, malgré son caractère « barbare », comme un grand homme.

En 1745, une lettre du roi de France est envoyée à Elisabeth, la France et la Russie tentent de renouer leurs relations. Voltaire envoie à l'impératrice russe son Henriade, en l'accompagnant des vers qui louent Elisabeth comme l'incarnation des vertus dont le héros de Voltaire a été un modèle ${ }^{46}$.

En même temps, sur les instances du représentant diplomatique de la France auprès de la cour russe, d'Allion, Voltaire se fait admettre à l'Académie des sciences pétersbourgeoise. Cette admission est due entièrement aux académiciens eux-mêmes. Ayant considéré le livre de Voltaire Eléments de la philosophie de Newton (1738, réédité en 1745), que celui-ci a présenté à l'Académie en exprimant son souhait d'y être admis, Nicolas-Joseph Delisle, qui était un adepte de la philosophie newtonienne, se prononce pour son élection à l'Académie à la séance du 24 février 1746. La décision est prise en faveur de Voltaire, mais un autre membre de l'Académie, le précautionneux Jacob Staehlin, propose d'attendre l'avis du chancelier de l'Empire, le comte Alexeї Bestoujev-Rioumine, ennemi de la France. A la réunion du 10 mars, la décision est aussi soutenue par Johann Daniel Schumacher, qui se trouve alors de fait à la tête de l'Académie : Schumacher veut «satisfaire Mr d'Allion ». Le chancelier répond enfin que l'Académie est libre d'élire ses membres sans demander le consentement des hautes autorités. Le 17 mars de la même année, l'élection de Voltaire dans la compagnie savante pétersbourgeoise est effective ${ }^{47}$.

Voltaire veut néanmoins plus : il souhaite qu'on lui envoie des documents sur Pierre le Grand car il a l'intention d'écrire son histoire. Il veut que d'Allion présente sa demande à l'impératrice, ce que le diplomate fait en 1746 comme il rapporte dans sa lettre adressée au marquis d'Argenson en janvier $1747^{48}$. Cependant, cette deuxième demande de l'écrivain ne

\footnotetext{
${ }^{44}$ Ibid.

${ }^{45}$ Frédéric parle à Voltaire de sa vision, désormais négative, de la figure de Pierre dans sa lettre du 13 novembre 1737. Е. Шмурло, Вольтер и его книга о Петре Великом, ор. cit., р. 24-26.

${ }^{46}$ Voir К. Осповат, «Из истории русского придворного театра 1740-х годов», Memento vivere: Cборник памяти Л. Н. Ивановой [K. Ospovat, «De l'histoire du théâtre de cour russe des années 1740 », Memento vivere : recueil en mémoire de L.N. Ivanova], sous la dir. de K.A. Koumpan et E.R. Obatnine, Saint-Pétersbourg : Naouka, 2009, p. 9-36, ici p. 11-12.

47 П.П. Пекарский, История императорской Академии наук в Петербурге [Petr Pékarski, Histoire de l’Académie impériale à Saint-Pétersbourg], vol. 1, St.-Pétersbourg : Izd. Akademii naouk, 1870, p. 381-383; Г.A. Князев, « Вольтер - почетный член Академии наук в Петербурге », Вольтер. Cтатьи и материаль [G.A. Kniazev, «Voltaire membre d'honneur de l'Académie des sciences de Pétersbourg ", Voltaire, articles et documents], sous la dir. de V.P. Volguine, Moscou-Leningrad : Izd. Akademii naouk SSSR, 1948, p. $307-313$.

$4^{8}$ П.П. Пекарский, История императорской Академии наук, ор. cit., p. 384.
} 
trouve pas d'écho favorable à Pétersbourg. Bestoujev-Rioumine considère alors que les grandes actions de Pierre ne doivent pas être mêlées à d'autres (celles de Charles XII, s'entend) et que la tâche d'écrire une histoire du grand empereur doit être confiée à l'Académie pétersbourgeoise plutôt qu'à un « étranger ${ }^{49}$.

En 1748, Voltaire fait paraître ses Anecdotes sur le czar Pierre le Grand ${ }^{50}$. L'écrivain accentue la barbarie de la Moscovie d'avant Pierre ce qui fait ressortir encore mieux le rôle du tsarréformateur. En même temps, il ne fait pas l'impasse sur la brutalité du tsar, sur son abus d'alcool, peignant un portrait qui est loin de l'icône consacrée par la propagande officielle russe. Ces Anecdotes aggravent certainement le dossier de Voltaire aux yeux des courtisans de Saint-Pétersbourg, ce qui se fait sentir dans le traitement que lui réserve le président de l'Académie pétersbourgeoise, le comte Kirill Razoumovski. Déjà en 1746, répondant à la lettre de l'académicien Gerhard Friedrich Müller, qui l'informait de son élection à l'Académie, Voltaire exprimait un souhait de venir à Saint-Pétersbourg. En réponse à une lettre de Voltaire par laquelle le philosophe congratulait le comte Kirill Razoumovski pour sa nomination à la tête de l'Académie des sciences (survenue en 1746), le comte, après les courtoisies d'usage, oppose au souhait de Voltaire un refus poli, mais catégorique (la lettre de Razoumovski est datée de janvier 1751$)^{51}$.

Après le traité d'Aix-la-Chappelle (1748), Frédéric II remplit ses écrits de propos vengeurs à l'encontre d'Elisabeth ${ }^{52}$. En 1751, il publie ses Mémoires pour servir à l'histoire de la maison de Brandebourg, très critiques envers la Russie de Pierre le Grand, que le roi de Prusse présente comme incapable de mettre les «bornes aux sentiments » de sa vengeance, entouré de gens corrompus comme Menchikov qui «auroit peut-être vendu son maître si le roi [Frédéric Guillaume] avoit voulu l'acheter », etc. Frédéric II y écrit à propos de Menchikov et du peuple russe : "Lui et toute cette nation étoient si barbares, qu'il ne se trouvoit dans cette langue aucune expression qui signifiât l'honneur et la bonne foi ${ }^{53}$. On n'ignorait bien sûr pas à Saint-Pétersbourg que Voltaire était un ami du roi de Prusse et qu'il avait contribué à certains de ses écrits. Les idées avancées par le roi dans ses Mémoires sont passés dans certains pamphlets prussiens du temps de la guerre de Sept ans $^{54}$ et piquaient bien entendu l'amourpropre des Russes. En témoigne notamment une lettre d'Ivan Chouvalov à Voltaire accompagnant l'envoi du Panégyrique de Lomonossov, dans laquelle Chouvalov dit que l'œuvre de Lomonossov doit montrer que le russe n'est pas une langue si pauvre que le disent les Mémoires de Frédéric II ${ }^{55}$.

\footnotetext{
${ }^{49}$ Е. Шмурло, Вольтер и его книга о Петре Великом, ор. cit., р. 38.

${ }^{50}$ Voltaire, «Les Anecdotes sur le czar Pierre le Grand », Euvres de Voltaire, Dresde, 1748, vol. 2, p. 242-256 et l'édition définitive de Michel Mervaud citée plus haut : Euvres complètes de Voltaire, op. cit., vol. 46. Voir à leur sujet l'introduction de Michel Mervaud à la publication des Anecdotes, Euvres complètes de Voltaire, op. cit., vol. 46, p. 3-49, ainsi que : Michel Mervaud, « Les Anecdotes sur le czar Pierre le Grand de Voltaire : genèse, sources, forme littéraire », SVEC, 1996, n³41, p. 89-126.

${ }^{51}$ П.П. Пекарский, История императорской Академии наук, ор. cit., p. 385.

${ }^{52}$ Francine-Dominique Liechtenhan, « Les espaces franco-russes de Frédéric II pendant la guerre de succession d'Autriche: essai d'histoire diplomatique", Philologiques IV. Transferts culturels triangulaires, FranceAllemagne-Russie, sous la dir. de Katia Dmitrieva et Michel Espagne, Paris : Maison des sciences de l'homme, 1996, p. 73-91, ici p. 74-75.

${ }^{53}$ Frédéric II, Mémoires pour servir à l'histoire de la maison de Brandebourg, Berlin : chez Chrétien Frédéric Voss, 1751, p. 171, 169. Frédéric pouvait faire cette conclusion en lisant Montesquieu qui affirme que l'honneur est « inconnu aux Etats despotiques, où même souvent on n'a pas de mot pour l'exprimer », De l'esprit des lois, t. 1, Paris, 1979, p. 150. Montesquieu puise cette information dans la relation de John Perry. Voir Michel Mervaud, « Le knout et l'honneur des Russes (à propos de deux articles de l'Encyclopédie) », Recherches sur Diderot et sur l'Encyclopédie, 1993, vol. 14(1), p. 111-124, ici p. 114.

${ }^{54}$ Comme le montre Kirill Ospovat : К. Осповат, «Государственная словесность», art. cit., p. 44-45.

55 The complete works of Voltaire, op. cit., vol. 46-47, Oxford, 1999, p. 117.
} 
L'opinion de Mikhaïl Lomonossov, qui en fait part dans une lettre adressée à Chouvalov du 3 octobre $175^{2}$, témoigne à mon avis non seulement de l'attitude personnelle du savant russe envers l'écrivain français, mais fait écho à ce qu'on pensait alors du grand écrivain français à Saint-Pétersbourg :

Je ne peux manquer d'expédier à Votre Excellence un nouveau rejeton monstrueux de la muse de Voltaire, - écrit Lomonossov en envoyant à Chouvalov l'Epître à M. le cardinal Quirini de Voltaire, parue en 1752 -, qui déclare que lui et son maître sont athées et qu'il ne craint pas de s'en vanter devant le monde entier. Pour constater combien cet homme d'esprit est sans esprit, combien son honneur est sans conscience, et ses louanges insultantes, on ne peut trouver meilleur exemple, dans tous les écrits de Voltaire, que ce libelle en forme de panégyrique, que je soumets à votre jugement clairvoyant, tout en restant le dévoué serviteur de Votre Excellence $^{56}$.

On peut douter que Lomonossov ait voulu exprimer son avis sur Voltaire avec autant de venin s'il avait su que son opinion ne coïncidait pas du tout avec celle de Chouvalov. On a même l'impression que le savant russe, connaissant l'attitude négative de sa cour envers Voltaire, cherche à la consolider par une nouvelle pièce versée au dossier déjà chargé de l'écrivain français ${ }^{57}$. On voit indirectement le reflet de cette attitude dans l'enquête ouverte en 1754 afin de comprendre qui était responsable de l'élection de Voltaire comme membre d'honneur de l'Académie pétersbourgeoise: Schumacher, qui a toujours été très attentif au vent qui soufflait à la cour, prépare alors pour le président de l'Académie un extrait du protocole de 1746 afin de démontrer que la faute revient entièrement aux académiciens et nullement à luimême ${ }^{58}$.

La situation change pourtant dans les années suivantes. En 1754, Voltaire se brouille avec Frédéric II et est même provisoirement emprisonné sur l'ordre de ce dernier. Avec le début des hostilités initiées par le roi de Prusse en Europe en 1756, Frédéric II est sévèrement critiqué par son ancien ami et des vers caustiques sur Frédéric sont attribués à Voltaire, y compris par des Russes : Mikhaïl Lomonossov, qui a pourtant dit tant de mal sur Voltaire, traduit ces vers en 1756 et cette traduction devient connue des membres du « parti français » à la cour russe, le vice-chancelier Mikhaïl Vorontsov l'envoie au représentant diplomatique russe à Paris ${ }^{59}$. De là à voir en Voltaire un allié possible dans la lutte propagandiste que les Russes commencent avec la France et l'Autriche contre le roi de Prusse, il n'y avait qu'un pas. Après tout, l'écrivain français n'était pas seulement un critique sévère des Russes : Voltaire a encensé la Russie d'Elisabeth et l'impératrice elle-même à plusieurs reprises. Dans son discours d'admission à l'Académie Française en 1746, il dit en s'adressant aux académiciens français :

Vos ouvrages, messieurs, ont pénétré jusquà cette capitale de l'empire le plus reculé de l'Europe et de l'Asie, et le plus vaste de l'univers ; dans cette ville qui n'était, il y a quarante ans, qu'un désert habité par des bêtes sauvages : on y représente vos pièces dramatiques ; et le même goût naturel qui fait recevoir, dans la ville de Pierre le Grand, et de sa digne fille, la

\footnotetext{
56 М.В. Ломоносов, Полное собрание сочинений [Mikhaïl Lomonossov, Euvres complètes], MoscouLeningrad : Académie des sciences de l'URSS, t. 3, 1952, p. 254, cité d'après Piotr Zaborov, Voltaire dans la culture russe, op. cit., p. 11.

57 Il est vrai que, même après la décision de confier une histoire de Pierre le Grand à Voltaire, Lomonossov tiendra Voltaire pour un « homme dangereux » (lettre à Ivan Chouvalov du 2 septembre, 1757).

${ }^{8}$ Г.А. Князев, «Вольтер - почетный член», art.cit., p. 313.

${ }^{59}$ К. Осповат, «Государственная словесность», art. cit., p. 30.
} 
musique des Italiens, y fait aimer votre éloquence ${ }^{60}$.

Même dans les Anecdotes sur le czar Pierre le Grand, qui contiennent pourtant tant de choses capables d'irriter Pétersbourg, l'image de la Russie élisabéthaine n'est pas celle de la barbarie et de l'ignorance, mais celle du progrès des sciences et des arts. Voltaire n'y écrit-il pas que le français est « devenu depuis la langue de Pétersbourg sous l'impératrice Elisabeth, à mesure que ce pays s'est civilisé $"{ }^{61}$ ?

Le nouveau rapprochement entre la France et la Russie, voulu par le «parti français », proposait un nouveau terrain pour les changements dans la politique de propagande culturelle orchestrée par Ivan Chouvalov ${ }^{62}$.

\section{L'Apothéose de Pierre le Grand}

Parmi les textes critiques sur Voltaire écrits à cette époque, trois ont particulièrement intrigué les historiens. Il s'agit des textes découverts et publiés par l'historien tchèque Václav Černý qui les a attribués à Mikhaïl Lomonossov en supposant qu'ils étaient destinés à Voltaire : ces deux suppositions ont même été inclues par Černý dans le titre du livre ${ }^{63}$. Les deux me semblent non seulement peu vraisemblables, mais impossibles ${ }^{64}$.

L'hypothèse de Černý, bien que défendue avec vigueur par certains historiens russes de la littérature à une séance spéciale de l'Institut de la littérature russe qui a eu lieu le 29 novembre 1963, a été critiquée par d'autres qui ont avancé contre elle des arguments solides que je ne reproduirai pas ici $^{65}$. Le manuscrit a été trouvé dans les archives du prince Lobkowicz chez qui il est parvenu de la famille d'Hermann Karl von Keyserling, ambassadeur de Russie à Vienne, qui a été, pendant une courte période, président de l'Académie des sciences pétersbourgeoise. Černý croyait que le manuscrit s'était trouvé chez les Keyserling parce que Heinrich Christian von Keyserling, fils de Hermann Karl, a été l'intermédiaire viennois entre Ivan Chouvalov et Voltaire, à qui Chouvalov envoyait des matériaux pour ce qui deviendrait une Histoire de l'empire de Russie sous Pierre le Grand. Cependant, cette version des faits semble impossible car l'un des trois textes est non seulement extrêmement critique, mais également outrageant pour l'historien. Est-il est concevable que Chouvalov ait pu envoyer à Voltaire un texte insultant pour l'amour-propre de l'écrivain, au risque de voir leurs relations rompues ${ }^{66}$ ? Il y a encore moins de raisons d'attribuer ce texte à Lomonossov. Il est

\footnotetext{
${ }^{60}$ Voltaire, « Discours de M. de Voltaire à sa réception à l’Académie Française », The Complete Works of Voltaire, vol. 3oA, Oxford: Voltaire Foundation, 2003, p. 28-30, cité d’après К. Осповат, «Государственная словесность», art. cit., p. 16.

${ }^{61}$ Voltaire, The Complete Works of Voltaire, vol. 46, Oxford, Voltaire Foundation, 1999, p. 55, cité d'après K. Осповат, «Государственная словесность», art. cit., p. 14.

${ }^{62}$ Sur le rapprochement diplomatique de la Russie et de la France, voir F.-D. Liechtenhan, Elisabeth I ${ }^{r e}$ de Russie, Paris, 2007.

${ }^{6}$ L’Apothéose de Pierre le Grand etc. Trois écrits historiques inconnus, présumés de M.V. Lomonosov, destinés à Voltaire, publiés d'après le manuscrit de Prague, avec une Introduction sur les relations de Lomonosov et Voltaire, par Václav Černý, professeur à l'Université, docteur ès lettres, Prague, Editions de l'Académie Tchécoslovaque des sciences, 1964.

${ }^{64}$ J'ai exposé mes arguments dans un article consacré au parcours russe de Tschudy : В. Ржеуцкий, «В тени Шувалова», art. cit., p. 107-110.

${ }^{65}$ Voir le résumé de cette discussion dans : В. Степанов, «О пражской находке проф. В. Черного», Русская литература, $\mathrm{n}^{\circ} 2,1964$, р. 214-216. D’autres arguments ont été avancés par P. Hoffmann, « Lomonosov und Voltaire », Studien zur Geschichte der russischen Literatur des 18. Jahrhunderts, B. 3, herausgegeben von Helmut Grasshoff und Ulf Lehmann, Berlin : Akademie Verlag, 1968, p. 417-425.

${ }^{66}$ V.S. Lioublinski était de cet avis en faisant souligner que le gouvernement russe ne pouvait pas envoyer à Voltaire un texte dans lequel l'écrivain était traité de menteur. В. Степанов, «О пражской находке проф.
} 
bien connu que le savant russe a participé à la collecte des matériaux sur Pierre le Grand pour Voltaire. En fait, c'est l'argument principal de V. Černý qui indique aussi qu'il existe des parallèles entre l'Apothéose de Pierre le Grand et l'un des textes écrits par Lomonossov, son Eloge de Pierre le Grand (Похвальное слово Петру), mais ces ressemblances se résument à des traits de Pierre qui étaient bien connus des contemporains. Il est vrai qu'il existe une ressemblance stylistique entre l'Apothéose et le Panégyrique de Pierre le Grand, traduction française du texte de Lomonossov et Černý fait à juste titre remarquer cette similitude ${ }^{67}$. Cependant, comme je l'ai montré ${ }^{6}$, l'original de Lomonossov et la traduction sont, du point de vue stylistique, très différents. L'auteur de cette traduction était le baron de Tschudy et le style du Panégyrique est en grande partie imputable au traducteur et non à l'auteur qui a été d'ailleurs très mécontent de cette traduction. Enfin, V. Černý propose de décoder la signature de l'auteur («le c. de L.») comme « le conseiller de Lomonossov». Cependant, une autre variante est également possible, qui renvoie à Tschudy : "le chevalier de Lussy », nom de plume souvent utilisé par le baron, hypothèse proposée au départ par V.L. Tchénakal ${ }^{69}$. Cependant, ni Tchénakal, ni d'autres participants à cette discussion n’ont avancé dans cette direction.

Les chercheurs n'ont apparemment pas fait très attention à quelques mots dans la dédicace à Chouvalov, qui ouvre le manuscrit : « ni la durée du tems, ni la distance du lieu n'effaceront jamais de ma Mémoire les marques de vos bontés et le gracieux accueil que vous mavés fait avant mon départ pour les païs étrangers $»^{70}$. Černý accepte que ces mots contredisent les faits de la vie de Lomonossov car le savant a connu Chouvalov bien des années après son séjour à l'étranger. En revanche, ces mots s'accordent parfaitement avec la biographie de Tschudy : c'est justement avant son départ pour la France que Tschudy se rapproche de Chouvalov et devient son secrétaire particulier. Le baron quitte Saint-Pétersbourg pour aller en France à la fin de l'année $1755^{71}$. Un agent secret de la France, La Meyssonnier de Valcroissant, confie à Tschudy deux lettres qu'il veut faire remettre à ses supérieurs à Varsovie, mais Tschudy les envoie à son protecteur Chouvalov. Valcroissant est saisi, mais la «trahison » de Tschudy devient connue des autorités françaises et il est arrêté à son tour en France en mai, passe deux mois à la Bastille avant d'être échangé contre Valcroissant grâce à l'insistance de son protecteur pétersbourgeois. S'il est remis fin juillet en liberté, il ne retourne pas en Russie tout de suite, mais reste assez longtemps en France, notamment afin de recruter des spécialistes pour la Russie. Son retour en Russie se situe au mois de mai de l'année suivante, 1757. Connaissant l'intérêt de son protecteur pour la figure de Pierre le Grand d'une part, et le regard critique porté sur Voltaire à Saint-Pétersbourg d'autre part, le baron continue son engagement pour l'image de la Russie. Entretemps on change de cap à Saint-Pétersbourg et,

В. Черного», art. cit., p. 216. Michel Mervaud est aussi de cet avis : Euvres complètes de Voltaire, op. cit., vol. 46, p. 115 .

${ }^{67}$ L’Apothéose de Pierre le Grand, op.cit., p. 183.

68 В.С. Ржеуцкий, «Барон де Чуди - переводчик М.В. Ломоносова. К истории перевода и переводчиков в России эпохи Просвещения», Ломоносов. Сб. статей и материалов [Vladislav Rjéoutski, «Le Baron de Tschudy, traducteur de Mikhail Lomonossov. Contribution à l'histoire de la traduction et des traducteurs en Russie », Lomonossov. Articles et matériaux], vol. 10, St.-Pétersbourg : Naouka, 2011, p. 269-280.

${ }^{69}$ Voir : В. Степанов, «О пражской находке проф. В. Черного», art.cit., p. 215. Tschudy utilise cette abréviation plusieurs fois dans son journal, par exemple, Caméléon littéraire, ${ }^{\circ}$ 3, du 19 janvier, 1755, p. 67.

${ }^{70}$ L'Apothéose de Pierre le Grand, op.cit., p. 72.

${ }^{71}$ Les événements qui ont accompagné ce départ ont été bien étudiés : А. Строев, Те, кто поправляет фортуну: Авантюристы Просвещения [Alexandre Stroev, Ceux qui corrigent la fortune : les aventuriers des Lumières], Moscou, 1998, en particulier p. 361-364 ; Antoine Nivière, « L'affaire Tschudi », Slovo, 200o, vol. 24-25, p. 297-396 ; В. Ржеуцкий, «В тени Шувалова», art. cit. 
au début de l'année 1757, Chouvalov propose à Voltaire d'écrire une histoire de Pierre le Grand. Se trouvant loin de Saint-Pétersbourg, Tschudy pouvait évidemment ignorer ce revirement.

On pourrait objecter que l'auteur de ces textes se présente comme un Russe ${ }^{72}$ : il dit que Chouvalov l'a chargé d'écrire des pièces pour le "Théâtre russien ", qu'il a entrepris d'écrire " un Poème épique en langue russienne sous le titre de Zaréide " ${ }^{73}$. Cependant, ce genre de jeu littéraire était dans l'air du temps et du goût de Tschudy qui, en faisant paraître le Caméléon littéraire, aimait prendre diverses identités. Il existe d'ailleurs un autre exemple tout à fait similaire : un autre Français proche de Chouvalov, le chevalier Dezessart, auteur d'un Voyageur moscovite, ou Lettres russes, se fait passer pour le traducteur de cette œuvre écrite, comme il l'affirme, au départ en russe ${ }^{74}$. L'excuse que fait l'auteur de l'Apothéose, à la fin de la préface, pour les fautes que lui, étranger, ne peut s'empêcher de faire contre l'orthographe et le génie de la langue française, fait aussi partie du jeu d'autant plus que le style de l'auteur est excellent, fluide et très authentique, ne trahissant aucunement une plume non-française ${ }^{75}$. Connaît-on d'autres textes littéraires de cette longueur et de cette qualité écrits en français par des Russes à cette époque?

On pourrait aussi remarquer une grande ressemblance stylistique entre le Caméléon littéraire et les trois textes publiés par Černý. On remarque par exemple l'intérêt pour l'Antiquité, partagé par Tschudy et l'auteur des trois textes, la présence chez les deux de certains thèmes qui leur sont chers comme le thème du sort malheureux d'un littérateur, etc. Comme le fait remarquer à juste titre V.L. Tchénakal, Tschudy a publié plusieurs articles consacrés à Pierre le Grand dans le Caméléon littéraire, il était donc de toute évidence intéressé par ce thème ou a reçu de Chouvalov l'ordre de le développer dans son journal. Tchénakal attire l'attention sur le fait que Tschudy tire dans son journal un parallèle entre Pierre le Grand et Licurgue comme le fait aussi l'auteur de l'Apothéose ${ }^{76}$; mais Tschudy fait de même en comparant Pierre le Grand et Alexandre le Grand comme le fait aussi l'auteur des textes publiés par Černý ${ }^{77}$. Tchudy utilise d'ailleurs le mot «apothéose » dans son journal en parlant de Pierre le Grand ${ }^{78}$.

Les trois textes publiés par Černý sont tous pénétrés d’idées répandues sur Pierre le Grand en Occident. L'auteur de ces textes a une haute opinion du rôle des étrangers auprès de Pierre : «On regardoit alors en Russie comme un espèce de crime d'en sortir. Il fallut donc recourir aux étrangers; par bonheur qu'il y an avoit déjà dans ce pays. » (suivent des

\footnotetext{
${ }^{72}$ En tout cas c'est de cette façon que certains participants à la discussion ont interprété les mots qui suivent.

${ }^{73}$ L'Apothéose de Pierre le Grand, op.cit., p. 72-73.

${ }^{74}$ Voir В. Ржеуцкий, В. Сомов, «Шевалье Дезессар, московский гувернер и писатель», Философский век. Просвещенная личность в российской истории. К 27-летию со дня рождения И.И. Шувалова. Материалы международной конференции [V. Rjéoutski, V. Somov, « Le chevalier Dezessart, précepteur et écrivain moscovite", Le siècle de la philosophie. La personnalité éclairée dans l'histoire russe. Pour le $270{ }^{e}$ anniversaire d'Ivan Chouvalov], sous la dir. de Tatiana Artemieva et Mikhail Mikechine, St.-Pétersbourg, 1997, p. 220-240.

${ }^{75}$ A cet égard, il est difficile d'accepter l'avis de Černý et de plusieurs historiens russes qui ont considéré que ces textes étaient mal écrits en français et qu'ils trahissent la plume d'un auteur russe.

${ }^{76}$ В. Степанов, «О пражской находке проф. В. Черного», art.cit., p. 215. Tchénakal n'indique pas l'article dans lequel Tschudy compare Pierre le Grand et Lycurgue. Le seul endroit où Pierre soit comparé à Lycurgue est, semble-t-il, dans l'«Ode à Sa Majesté Impériale de toutes les Russies. Par Monsr. Darnauld, conseiller d'ambassade de Sa Majesté le Roi de Pologne, Electeur de Saxe et membre de l'Académie des sciences de Berlin. », Caméléon littéraire, $\mathrm{n}^{\circ}$ 42, du 26 octobre 1755, p. 961-981, ici p. 974 : «Quel est ce Demi-Dieu[,] c'est Pierre lui même, / Ce Licurgue des Rois, l'honneur du diademe ».

${ }_{77}$ Par exemple, Caméléon littéraire, $\mathrm{n}^{\circ}$ 1, 1755, p. 5-7; $\mathrm{n}^{\circ}$ 3, du 19 janvier, 1755, p. 65-67.

${ }^{78}$ Caméléon littéraire, $\mathrm{n}^{\circ}{ }^{1}, 1755$, p. 11.
} 
dithyrambes adressés à François Lefort) ${ }^{79}$. Il est aussi extrêmement critique envers les Russes d'avant Pierre $\mathrm{I}^{\mathrm{er}}$ : « des sujets si nombreux, plongés dans les ténèbres de l'ignorance, esclaves du préjugé, peu dociles, bien moins civilisés qu'agguerris. " ${ }^{80}$ Ces vues ne correspondent pas du tout à la position de Lomonossov. Celui-ci n'écrira-t-il pas dans son Histoire ancienne de la Russie : «On a beaucoup de témoignages qu'il n'y avait pas en Russie un tel règne d'ignorance comme le présentent certains écrivains étrangers ${ }^{81}$ ? On sait que Lomonossov a justement critiqué Voltaire pour avoir exagéré le rôle de Lefort et d'autres étrangers ${ }^{82}$. Les vues de l'auteur des trois textes publiés par Černý ne semblent pas non plus correspondre à ce qu'on sait des idées de Pavel Lévachev, un diplomate russe qui a été proposé par Pavel Berkov comme l'auteur possible de ces trois textes. En effet, en 1757, se trouvant à Vienne, Lévachev traduit l'œuvre de François de Callière De la Manière de négocier avec les souverains ${ }^{83}$. Dans la préface qu'il ajoute et qui est intitulée «Un mot adressé aux vrais patriotes », Lévachev souligne la nécessité d'attirer dans le service diplomatique russe non pas des étrangers, mais des «fils naturels de la patrie » («природных сынов отечества») ${ }^{84}$. Par ailleurs, on ne sait rien des écrits de Lévachev en français, sa correspondance publiée est, semble-t-il, toute rédigée en russe ${ }^{85}$. Il me semble donc que ces trois textes devraient être attribués au secrétaire d'Ivan Chouvalov.

D'après les indices que leur auteur nous donne, notamment dans la dédicace à Chouvalov, on peut conclure qu'il les a écrits à l'étranger et non pas en Russie. On peut donc situer l'écriture de ces textes entre l'été 1756 , quand Tschudy se trouvait à la Bastille, puis en est sorti, et avril 1757 environ, quand il devait se mettre en route pour retourner en Russie ${ }^{86}$. Il est probable que Tschudy, ayant reçu de Chouvalov la promesse du poste de secrétaire de l'université de Moscou, voulait faire un cadeau littéraire à son protecteur.

La teneur des propos de Tschudy dans ces trois textes nous en dit long sur ce qu'il savait des intentions de Chouvalov avant son départ pour la France. Ces textes sont consacrés à la figure de Pierre le Grand. Bien entendu, Pierre est particulièrement vénéré sous le règne d'Elisabeth, qui est sa fille. Mais pour Chouvalov il s'agit d'un thème qu'il entend exploiter pour améliorer l'image de la Russie : Pierre le Grand est le plus connu des monarques russes et celui qui a reçu les meilleurs suffrages auprès des écrivains européens. On sait que plusieurs écrivains dans l'entourage de Chouvalov s'emparent de ce sujet à la même époque : le même Dezessart, qui dédie à Chouvalov son Voyageur moscovite ${ }^{87}$ dans lequel il loue les mérites de Pierre le

\footnotetext{
${ }^{79}$ L'Apothéose de Pierre le Grand, op.cit., p. 77-78.

${ }^{80}$ Ibid., p. 78.

${ }^{81}$ М.В. Ломоносов, Полное собрание сочинений [Mikhaïl Lomonossov, Euvres complètes], vol. 6, MoscouLeningrad, 1952, p. 170.

${ }^{82}$ Ф.Я. Прийма, Русская литература на Западе, ор. cit., p. 59, 61.

${ }^{83}$ De la Manière de négocier avec les souverains, de l'utilité des négociations, du choix des ambassadeurs et des envoyez, et des qualitez nécessaires pour reüssir dans ces employs, par Monsieur de Callières. Nouvelle Edition, Considerablement augmentée par $M^{* * *}$ Ryswick: Chez la Compagnie des Libraires, 1757, 2 parties. Н.Д. Кочеткова, «Левашев Павел Артемьевич», Словарь русских писателей XVIII века [N.D. Kotchetkova, «Lévachev Pavel Artemiévitch », Dictionnaire des écrivains russes du XVIII ${ }^{e}$ siècle], vol. 2, St.-Pétersbourg, 1999, URL : http://lib.pushkinskijdom.ru/Default.aspx?tabid=1084 (consulté le 20.09.2016).

${ }^{84}$ Н.Д. Кочеткова, «Левашев Павел Артемьевич», art. cit.

${ }^{85}$ Архив кн. Ф.А. Куракина, vol. 7, Saratov, 1898, p. 268, 296-297 ; vol. 9, Astrakhan, 1901, p. 287, 394, 407, 411, 412. Voir aussi П.А. Дружинин, Неизвестные письма русских писателей кн. А.Б. Куракину [P.A. Droujinine, Des lettres inconnues d'écrivains russes au prince A.B. Kourakine], Moscou, 2002.

${ }^{86}$ La date de 1758 , souvent avancée comme la date possible de la rédaction de ce texte, ne repose que sur le fait que le manuscrit s'est trouvé chez les Keiserling cette année (L’Apothéose de Pierre le Grand, op.cit., p. 162-165), or il pouvait de toute évidence être rédigé avant.

${ }_{87}$ « Le Voïageur Moscovite ou Lettres Russes : ouvrage Histori-Politi-critique Traduit du Russe Par M. M. chev.
} 
Grand ; le chevalier de Mainvilliers, ami de Tschudy, accepté par Chouvalov comme professeur à l'école de l'université de Moscou, qui écrit sa Pétréade ${ }^{88}$; mais aussi Lomonossov, qui prononce en 1755 son Panégyrique à Pierre le Grand, traduit par Tschudy et envoyé à Voltaire...

Un des trois textes publiés par Černý est une comparaison entre Pierre le Grand et quelques figures antiques: Alexandre le Grand et Lycurgue. La première comparaison souligne ses talents d'homme de guerre et de souverain, la deuxième, ses mérites de législateur. Enfin le troisième texte, intitulé Réfutation contre les auteurs qui ont fait dans leurs ouvrages des mentions desavantageuses et tout à fait fausses, touchant la vie et les actions de ce grand Monarque, mérite particulièrement notre attention ${ }^{89}$.

Quelques auteurs mentionnés dans ce texte, qui passent pour des anonymes, ont été identifiés par Černý : l'auteur de la Réfutation critique en particulier Mauvillon ${ }^{90}$ et l'histoire de Brandebourg écrite par Frédéric II $^{91}$, mais l'absolue majorité des passages sont consacrés à l'Histoire de Charles XII de Voltaire, dans l'édition de 1739. On peut penser que la présence du premier doit créer l'impression que l'attaque n'est pas dirigée uniquement contre Voltaire. Quant au deuxième texte, il s'agit d'un de ses ouvrages qui irritaient particulièrement SaintPétersbourg car Frédéric II était un ennemi personnel d'Elisabeth. De plus, il était connu que Voltaire avait contribué à la rédaction de ce texte.

La Réfutation attaque différentes affirmations de Voltaire concernant surtout la bataille de Narva, celle de Poltava et la campagne du Prouth ${ }^{92}$. Comme le note Sergueï Mézine, l'auteur exagère certains chiffres, mais dans d'autres cas (comme le nombre des troupes russes à Poltava), il dispose d'informations assez exactes. Ignorant certains faits historiques, il semble avoir eu accès à quelques sources peu connues ou inédites à l'époque comme la "Réflexion » du baron Chafirov et le « Journal du tsar Pierre $\mathrm{I}^{\mathrm{er}}$ » du baron von Huyssen ${ }^{93}$. Mais rappelons que Tschudy, par ses fonctions auprès de Chouvalov, pouvait avoir accès à ces documents et qu'il maîtrisait déjà dans une certaine mesure le russe comme le prouve sa très habile traduction de l'Eloge de Pierre le Grand de Lomonossov en 1758-1759.

L'un des objets de sa critique est le traitement par Voltaire de l'histoire de la rébellion des streltsy et de celle de la mort du tsarévitch Alexis qui, l'auteur le dit lui-même, créaient l'impression d'un souverain cruel, sanguinaire et barbare. Ce sont des sujets qui ont toujours posé problème et qui poseront encore problème à Voltaire quand il écrira son Histoire de l'empire de Russie sous le règne de Pierre le Grand. Les arguments que donne Tschudy - à supposer que c'est lui qui écrit ce texte - ne sont pas inintéressants. Une partie d'entre eux se réfèrent à l'histoire de la Russie : la profession du bourreau était méprisée en Russie, dit Tschudy, donc Pierre ne pouvait pas prendre lui-même la hache. Il rentrait d'un voyage en Europe occidentale ce qui aurait dû le rendre plus souple et plus humain. On voit que Tschudy donne des arguments fondés sur le bon sens, non sur la vérité historique et qu'il sous-entend une opposition de la Russie, pays encore peu civilisé, et de l'Europe occidentale. Mais la

\footnotetext{
des Essarts », Bibliothèque nationale de Russie, Manuscrits, Fr. Q XV, 38.

${ }^{88}$ La Pétréade, ou Pierre le créateur, par Mr. G.-S. chevalier de Mainvilliers, Amsterdam : J. H. Schneider, 1762 (rééd.: 1763). Etant donné les dimensions de ce poème épique, premier du genre consacré à Pierre le Grand dans la littérature française, on peut supposer que Mainvilliers a commencé son écriture bien avant cette date, probablement dès son arrivée en Russie en 1756 et son engagement en qualité de professeur de politique et d'héraldique à l'école préparatoire dépendant de l'université de Moscou.

${ }^{89}$ L'Apothéose de Pierre le Grand, op.cit., p. 109-145.

${ }^{90}$ E. Mauvillon, Histoire de Pierre I, surnommé le Grand, empereur de toutes les Russie, roi de Sibérie, de Casan, d'Astracan, grand-duc de Moscovie etc. etc., Amsterdam et Leipzig, 1742.

${ }^{91}$ Mémoires pour servir à l'histoire de Brandebourg, Berlin et La Haye, 1751.

${ }^{22}$ Voir l'analyse de la Réfutation dans C.A. Мезин, Взгляд из Европы: французские авторы XVIII века о Петре I [Sergueï Mézine, Regard d'Europe : les auteurs français du XVIIIe siècle sur Pierre I ${ }^{e r}$ ], Saratov, 2003, chapitre 3. ${ }^{93}$ Ibid.
} 
nécessité de punir les rebelles est indiscutable pour lui, elle s'explique par la fatalité du temps et des circonstances et ne contredit pas les lois divines et les lois de la nature ${ }^{94}$. Quant à l'histoire de la mort du tsarévitch Alexis, Pierre le Grand y joue le rôle le plus noble. Il ne pouvait pas condamner à la mort son propre fils après toutes les belles institutions qu'il avait fondées dans ses Etats. Mais même si Pierre est coupable de la mort de son fils, on ne peut pas l'en blâmer : il l'a sacrifié pour le bien de son peuple et mérite les mêmes louanges que Brutus, que tout le monde révère ${ }^{95}$.

Les remarques critiques s'adressent à l'auteur de l'Histoire de Charles XII, alors que les Anecdotes sur le czar Pierre $I^{e r}$ ne sont même pas mentionnées. Voltaire est traité $\mathrm{d}^{\prime}$ " " historien-poète », donc quelqu'un qui est le contraire d'un historien. Aucun auteur, affirme Tschudy, n'a écrit un portrait aussi noir du grand tsar. Ce qui frappe dans l'acharnement de l'auteur de la Réfutation, c'est qu'il est injuste envers Voltaire car celui-ci met souvent Pierre le Grand plus haut que Charles XII ${ }^{96}$. Si Voltaire n'essaie pas de transformer, comme Tschudy, la mort du tsarévitch Alexis en un conte touchant qui fait pleurer les lecteurs apitoyés par le sort du père qui perd son enfant, il reconnaît aussi la nécessité de ce sacrifice ${ }^{97}$. Si l'on se souvient du traitement de la figure de Voltaire par Tschudy dans son journal, un jour admiration, un autre jour critique acerbe, on peut dire qu'ici Tschudy essaie de remplir pleinement les attentes de son protecteur supposant que Voltaire est toujours une persona non grata à Saint-Pétersbourg.

\section{Conclusion}

En analysant ces quelques publications, aussi bien celles qui paraissent dans la presse francophone éditée en Russie que dans des sources restées inédites à cette époque, on peut faire quelques conclusions.

La première concerne l'attitude à l'égard de Voltaire à la cour de Russie avant la commande de l'Histoire de l'empire de Russie sous Pierre le Grand, qui lui est faite au début de l'année 1757. Les articles critiques publiés par Tschudy dans son journal permettent de supposer que cette attitude est très négative : Tschudy est un admirateur de Voltaire ; s'il change de ton à l'égard de son idole, c'est parce que ses propos n'ont pas plu aux lecteurs pétersbourgeois, sans doute mécontents du traitement par Voltaire du souverain russe dans ses œuvres, avant tout dans les Anecdotes sur le czar Pierre le Grand et dans son livre sur Charles XII.

La deuxième conclusion concerne l'image de Pierre le Grand. Les publications de Tschudy, ainsi que plusieurs autres publications faites à la même époque aussi bien par des Français que par des Russes se trouvant dans l'entourage de Chouvalov, montrent que Pierre le Grand n'est pas qu'un élément rhétorique du discours pétersbourgeois, c'est l'un des piliers, voire le pilier de la «propagande » russe telle qu'elle est organisée par Ivan Chouvalov. En effet, sous Elisabeth, fille de Pierre, il y a une sorte de déification du grand empereur en Russie. Avant de s'adresser à Voltaire, Ivan Chouvalov fait déjà de la figure de Pierre le Grand une utilisation qui est à peu près telle qu'elle sera dans les relations avec Voltaire. La différence est cependant de taille: les littérateurs qui offrent leurs plumes à Chouvalov (Mainvilliers, Tschudy, Dezessart, Lomonossov et d'autres), s'ils ont un certain talent littéraire, sont peu, voire pas du tout connus de l'Europe littéraire et ne peuvent pas porter le message de Pétersbourg dans

\footnotetext{
${ }^{94}$ L'Apothéose de Pierre le Grand, op.cit., p. 111-113.

${ }^{95}$ L'Apothéose de Pierre le Grand, op.cit., p. 114, 116.

${ }^{96}$ Euvres complètes de Voltaire, vol. 46, op. cit., p. 114.

${ }^{97}$ L’Apothéose de Pierre le Grand, op.cit., p. 120.
} 
toute l'Europe comme le peut Voltaire.

Après avoir exprimé, par la voie de Tschudy, le mécontentement de ce que Voltaire disait de Pierre le Grand, la cour de Russie demande au grand écrivain de devenir l'historiographe officiel de l'empereur. Si l'on admet que les textes publiés par Černý ont été écrits par Tschudy, il faut admettre aussi que, lors de son absence de Saint-Pétersbourg en 1756 et 1757, Tschudy continue son travail pour Chouvalov en partant du principe que Voltaire est toujours l'antagoniste de la cour de Russie. Pendant ce temps-là, le vent a tourné à Saint-Pétersbourg et l'on prend le parti de faire de Voltaire un allié. L'ironie de cette histoire est que Tschudy est lui-même un admirateur du grand écrivain et cherche à trouver des arguments contre Voltaire tout en lui empruntant bien des éléments, par exemple sa comparaison entre Alexandre le Grand et Pierre le Grand. Ironie du sort encore, c'est Tschudy qui, à son retour en Russie, sera chargé par Chouvalov de coordonner le travail de collecte de matériaux historiques pour Voltaire $^{98}$ !

Les indications dans le journal de Tschudy me semblent donc extrêmement importantes pour comprendre l'évolution des relations de la cour de Russie avec Voltaire et la politique générale de cette cour pour l'amélioration de l'image de la Russie en Europe. Ces relations sont ambigües et changent en fonction de l'appréciation de ce que Voltaire écrit sur Pierre le Grand et sur la Russie, aussi bien qu'en fonction de la situation politique générale en Europe et de la position particulière de Voltaire vis-à-vis de l'ennemi d'Elisabeth, Frédéric II. Cette histoire permet aussi de voir quel rôle la presse francophone naissante de Saint-Pétersbourg et de Moscou occupe dans cette politique. Chouvalov mise sur cette presse pour porter la bonne nouvelle de la cour de Russie. Il peut en effet la contrôler (tant bien que mal) : si le Caméléon littéraire n'est pas dicté par le Palais, il prend néanmoins en compte l'avis des personnages importants auxquels le baron de Tschudy est lié. Cependant il est douteux que cette presse pût porter loin la parole de Saint-Pétersbourg: on ne sait rien de la diffusion de ces périodiques en dehors de la Russie. C'est probablement l'un des arguments qui font à Chouvalov prendre la décision de changer de stratégie et de s'adresser à Voltaire.

${ }^{98}$ Voir sur ce rôle de Tschudy : Michel Mervaud, « Des matériaux pour Voltaire », art. cit. 